\title{
Diagnosis of adenoid cystic carcinoma in the breast: a case report and literature review
}

Zihui Liư ${ }^{1}$, Minghui Wang ${ }^{2}$, Yan Wang ${ }^{1}$, Xingbin Shen ${ }^{1}$, Chunhui Li ${ }^{1}$

\author{
${ }^{1}$ Department of Pathology, The Affiliated Hospital of Chengde Medical College, \\ Chengde, Hebei Province, China \\ 2Department of Breast Surgery, The Affiliated Hospital of Chengde Medical College, \\ Chengde, Hebei Province, China
}

Submitted: 5 November 2021; Accepted: 29 November 2021

Online publication: 14 January 2022

Arch Med Sci 2022; 18 (1): 279-283

DOI: https://doi.org/10.5114/aoms/144321

Copyright $\odot 2021$ Termedia \& Banach

Based on the comprehensive examination, the lump was considered to be a benign breast tumor in the first visit registration (Figure 1). The advice given was to closely observe any changes in the tumor, and it was also decided that surgical treatment was necessary. On August $6^{\text {th }}, 2018$, this patient visited the outpatient department again. She said that the tumor had slowly increased in size and was tender. The second physical examination showed the tumor to be $2 \times 2 \mathrm{~cm}$. Breast color ultrasonography revealed a $21 \mathrm{~mm} \times 19.6 \mathrm{~mm} \times 10.7 \mathrm{~mm}$ hypoechoic lesion at 12 '-1'clock in the right breast, $31 \mathrm{~mm}$ from the nipple, with unclear boundaries and irregular shapes (Figure 2). The color Doppler flow imaging (CDFI) found a scattered blood flow signal in the hypoechoic lesion (Figure 2). The BI-RADS level was raised to 4 a. A computed tomography (CT) chest scan demonstrated a soft tissue mass with irregular shapes in the upper quadrant of the right breast. The mass was present in the adipose tissue of the chest wall but had caused no skin changes. Nor was any palpable axillary lymphadenopathy detected. Mammography revealed a large irregular dense shadow above the right nipple, which was slightly retracted, hence the BI-RADS level 4a (Figure 3). Subsequently, the patient was recommended to have surgical treatment as an inpatient. The patient had no family history of breast disease or any other type of tumor. The detection of tumor markers showed that serum carbohydrate antigen (CA) 125 was $15.83 \mathrm{U} / \mathrm{ml}$, CA $15-3$ was $8.32 \mathrm{U} / \mathrm{ml}$, and carcinoembryonic antigen (CEA) was $2.9 \mathrm{ng} / \mathrm{ml}$, all of which were within normal ranges. On August $8^{\text {th }}, 2018$, the pathological evaluation of a coarse needle puncture cytology test revealed a particular type of invasive carcinoma of the breast, namely adenoid cystic carcinoma. On August $13^{\text {th }}$, 2018, a sentinel lymph node biopsy and breast-conserving surgery were performed. The sentinel lymph node was negative for metastasis, but a histopathologic examination confirmed adenoid cystic carcinoma of the breast (Figure 4). With regard to the immunohistochemistry, the tumor cells were negative for estrogen receptor (ER), progesterone receptor (PR), human epidermal growth factor receptor 2 (HER2), actin, and calponin (Figure 5), but positive for P63 and partly positive for smooth muscle actin (SMA) and CD117 (C-kit) (Figure 6). The proliferation index (Ki-67) was approximately 10\% (Figure 6). The patient underwent four cycles of adjuvant chemotherapy using cyclophosphamide and epirubicin, and

\author{
Corresponding author: \\ Dr. Chunhui Li \\ Department of \\ Pathology \\ The Affiliated Hospital \\ of Chengde \\ Medical College \\ 36 of Nan Ying Zi St \\ Chengde \\ Hebei Province, China \\ E-mail: jinshishi753@163.com
}



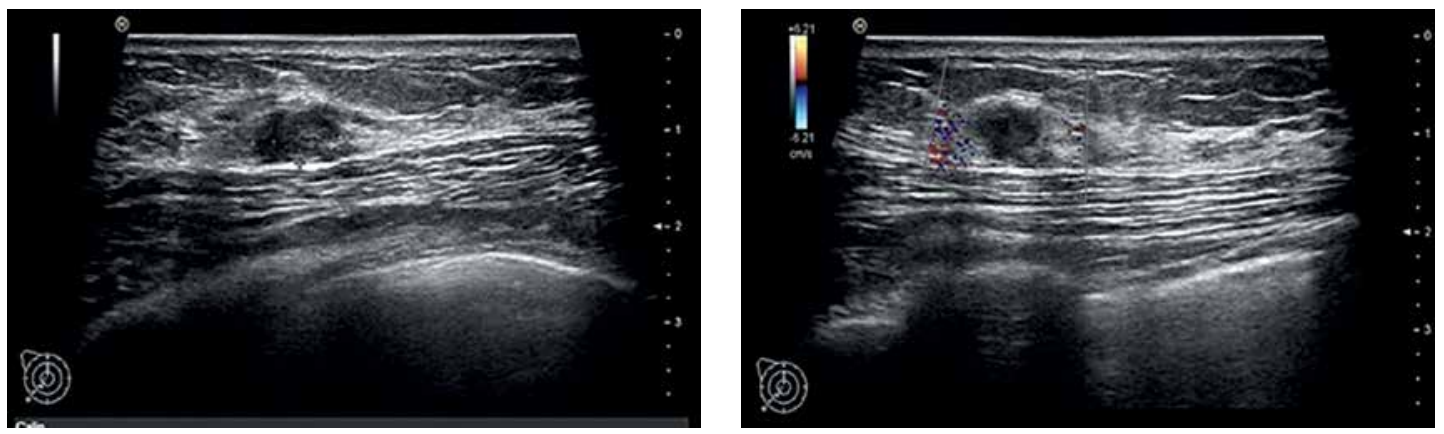

Figure 1. The first breast color ultrasonography image showing a hypoechoic lesion in the right breast. The color Doppler flow imaging (CDFI) found no obvious blood flow signal
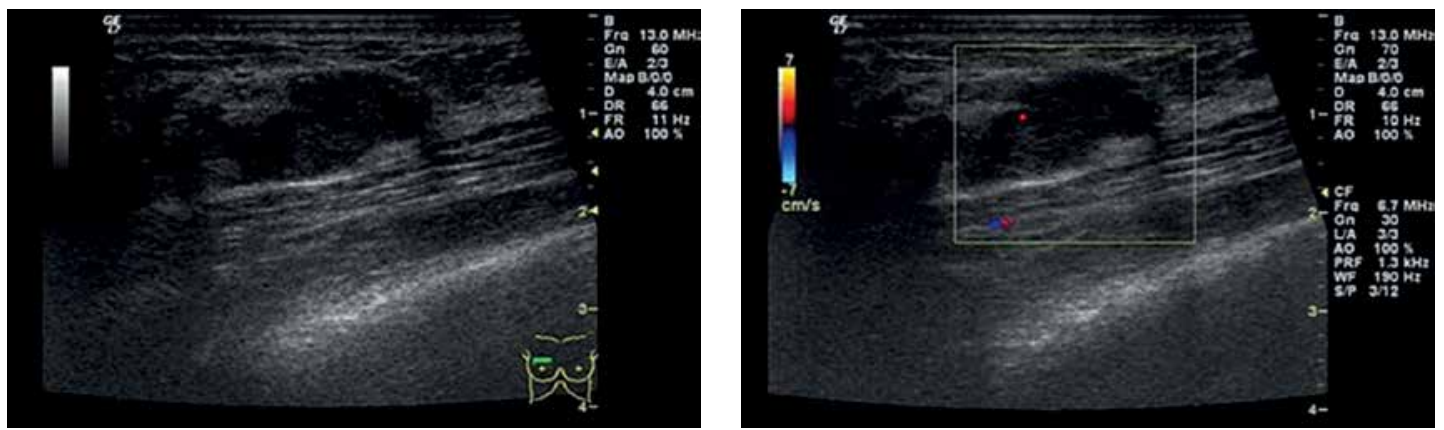

Figure 2. The second breast color ultrasonography image showing a bigger hypoechoic lesion in the right breast. The color Doppler flow imaging (CDFI) found a scattered blood flow signal

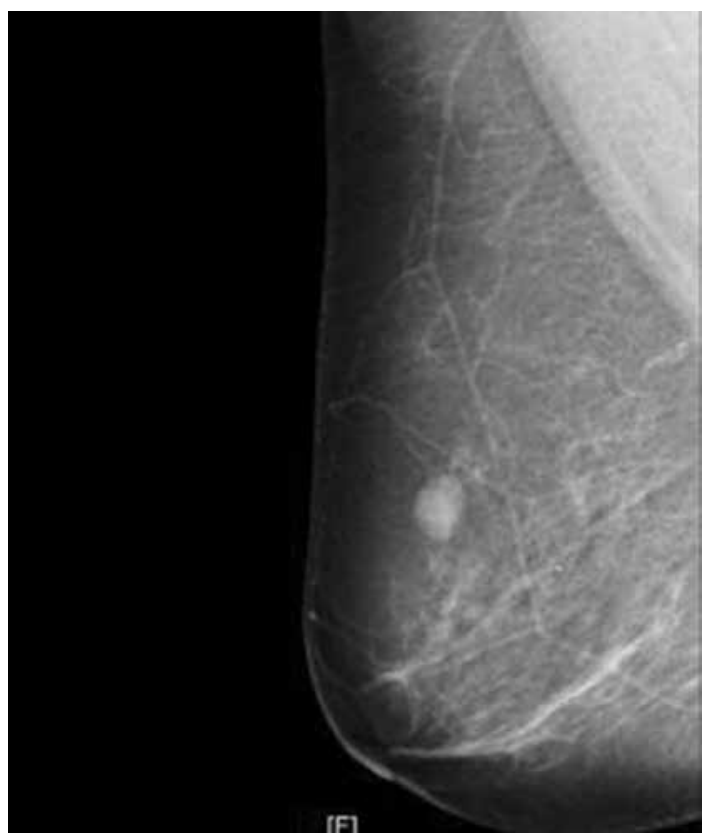

Figure 3. A mammography image showing a high density, irregular mass in the right breast

subsequently received adjuvant radiation therapy. There have been no obvious signs of tumor recurrence and metastasis up to now, and she will continue with regular follow-ups.

Adenoid cystic carcinoma is common in the salivary glands, but it is a rare form of invasive breast cancer, accounting for less than $0.1 \%$ of breast carcinomas [1, 2]. During a 6-year period (20132019) in our hospital, of 1,732 patients who were admitted to our department with a breast malignancy, only one was diagnosed as having adenoid cystic carcinoma of the breast (breast-ACC) (0.05\%). Such patients are almost always female (rarely male), the age at diagnosis is 30-90 years old, and the median age is 64 years [1]. BreastACC affects both breasts equally, and there is no predilection for the breast quadrant. Most tumors are found around the subareolar region [3], they grow slowly, and there is no representative symptom when the patient is confirmed as having breast-ACC. Only a few cases have been detected with spontaneous pain, which may be attributable to the perineural sensory invasion of the tumor [4] as was the case of the patient in this case report. McClenathan and de la Roza [5] analyzed 22 cases and discovered that 10 patients primarily complained of pain.

The relevant clinical examinations for breastACC lack specificity, with breast color ultrasonography and mammography normally being used in clinical practice. Breast color ultrasonography of breast-ACC mostly shows a benign-looking tumor with a clear boundary, the echoes inside the tumor are even, and color blood flow signals are occasionally seen. Mammography often shows irregular or lobulated masses with a higher density than the surrounding glands and clear or unclear edges. Such masses would be graded as BI-RADS 

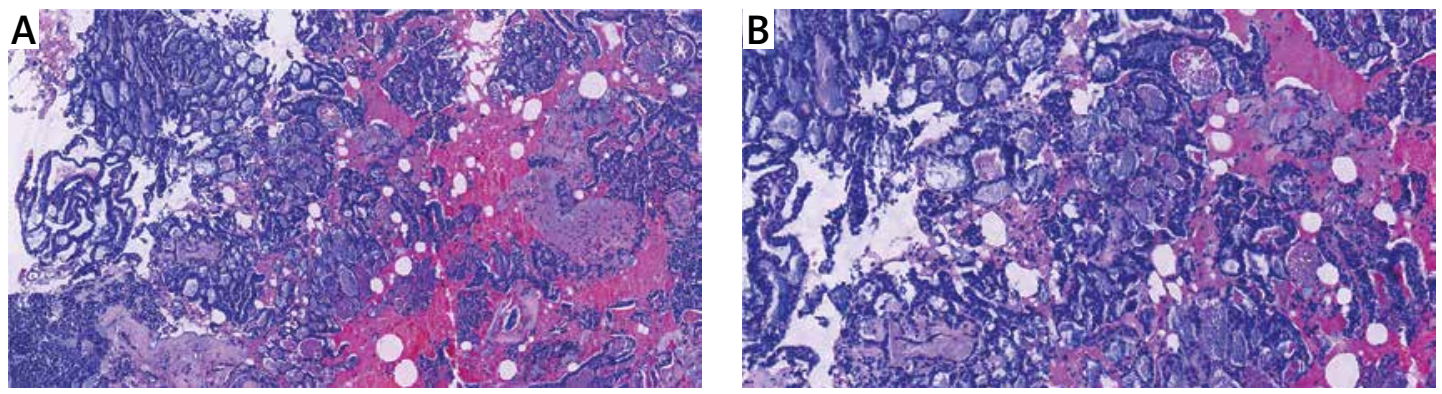

Figure 4. The clinicopathological features of breast-ACC, cribriform architecture, which are filled with mucinous material (A - H\&E stain 100x, B - H\&E stain 200x)
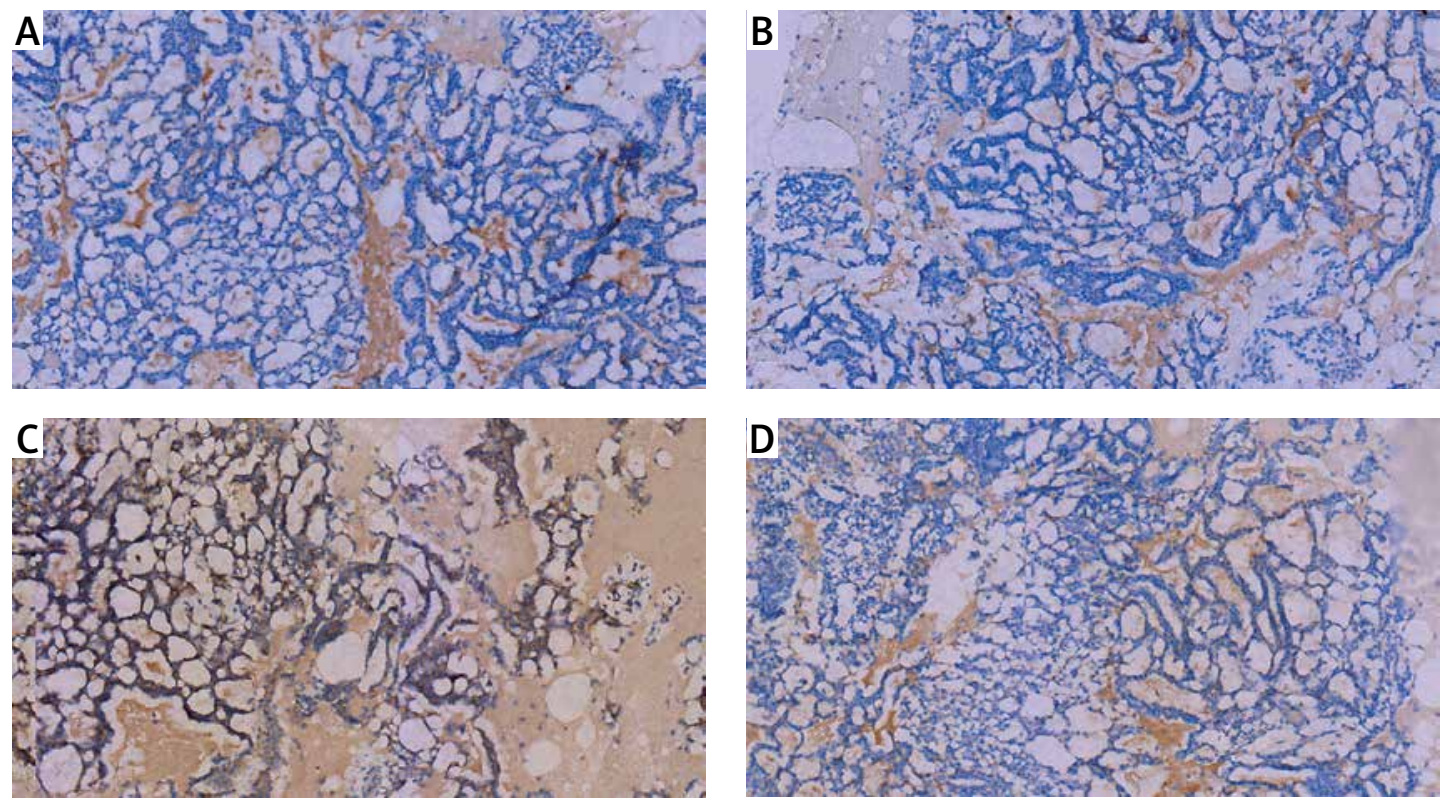

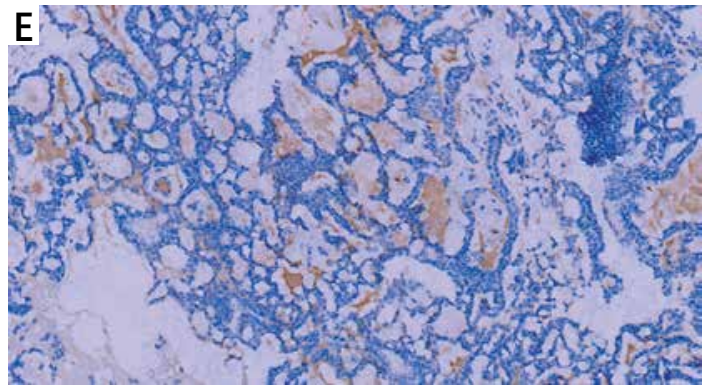

levels 3-4b. The case report patient demonstrated most of these features, which is why it was suggested that she attend regular follow-ups at first. Due to the obvious enlargement of the tumor and obvious tenderness during the follow-up, further treatment was deemed necessary. The tumor size can be from 0.5 to $12 \mathrm{~cm}$ (the average being $3 \mathrm{~cm}$ ), which is macroscopically seen as grey microcysts [6]. The histology of breast-ACC is very similar to that of the salivary gland, lung and skin [1], and the tumor is formed of epithelial and myoepithelial cell types arranged into three architectural patterns: classic tubular, cribriform architecture, and solid-basaloid $[1,2,6]$. The cribriform archi-
Figure 5. Tumor cells are negative for ER $(\mathbf{A}-\mathrm{IHC}$; 200x), PR (B - IHC; 200x), HER-2 (C - IHC; 200x), Actin (D - IHC; 200x) and Calponin (E - IHC; 200x)

tecture is most characteristic. The neoplastic cells are polarized around two types of structures: true glandular spaces and pseudolumina [1]. True glandular spaces, surrounded by luminal cells, are small, difficult to see, and contain neutral periodic acid-Schiff (PAS)-positive mucin. Pseudolumina, which are formed by intratumoral interstitial invagination, are surrounded by basal-myoepithelial cells, which are of varying shapes, but mostly round, and contain a myxoid acidic stromal substance that stains with Alcian blue or straps of collagen with small capillaries [1]. In the present case, the dominant type was observed as cribriform architecture, with some parts presenting as 

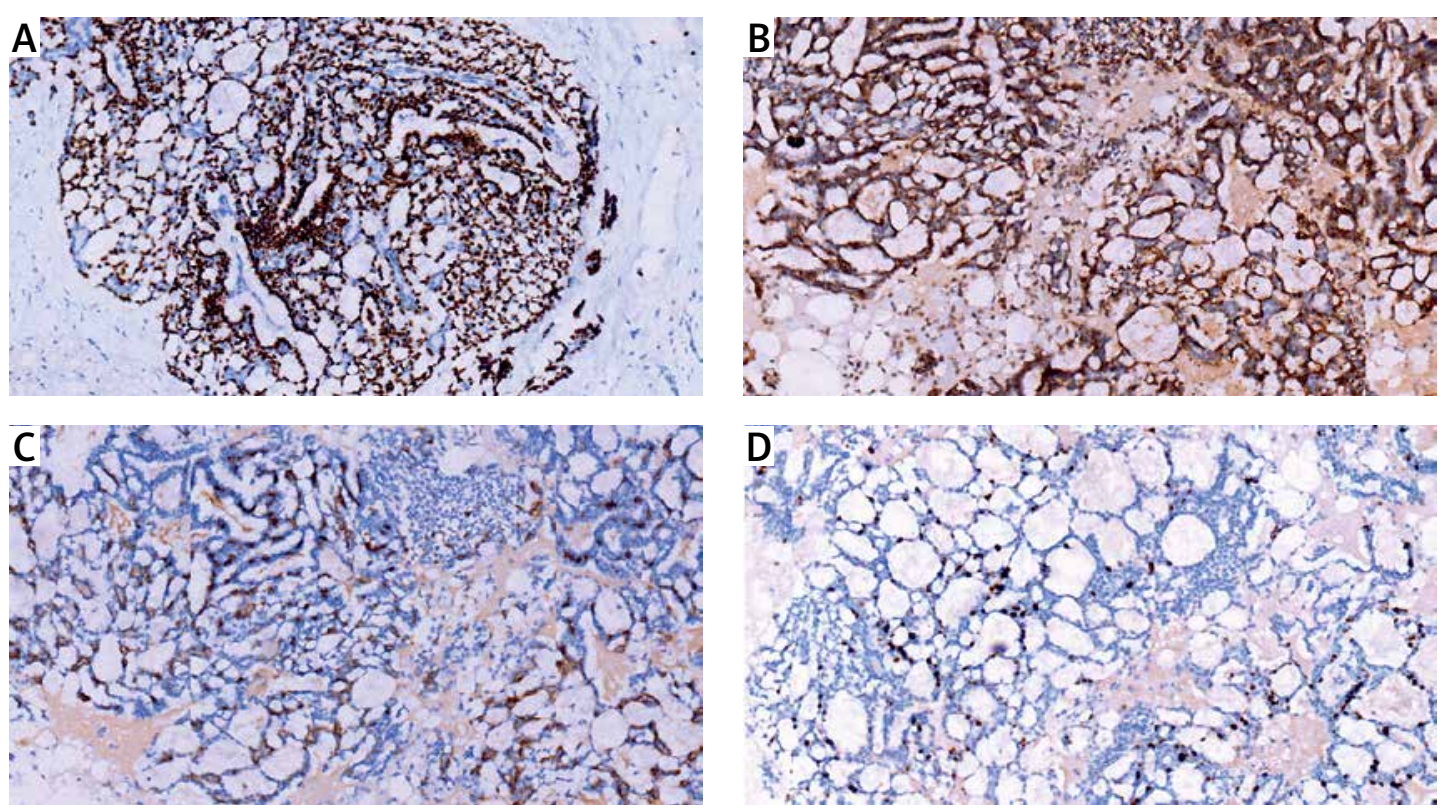

Figure 6. Tumor cells are positive for P63 (A - IHC; 200x), SMA (B - IHC; 200x), CD117 (C - IHC; 200x) and Ki-67 (D - IHC; 200x)

solid-basaloid (Figure 4). The cribriform pattern was composed of cylindromatous microcystic spaces filled with basophilic mucoid material. In the solid-basaloid areas, sheet structures of uniform basaloid cells lacking tubular or microcytic formation were also observed. Immunohistochemically, the patient's receptor status was as follows: ER, PR, HER-2, actin, and calponin were all negative, SMA and C-kit were partly positive, P63 was positive, and $\mathrm{Ki}-67$ was $10 \%$ positive. The luminal cells were positive for $C K 7, C K 8 / 18$, epithelial membrane antigen, and CD117 [7, 8]. The basal-myoepithelial cells were positive for p63, actin, calponin, SMA and S-100 protein [7-9]. Phenotypically, both luminal and basal-myoepithelial cells in breast-ACC are generally negative for ER, PR, and Her2 proteins, and the immunohistochemical profile of breast-ACC fits well within that of triple-negative breast cancer (TNBC) with basal-like features [2]. Although TNBC generally has high proliferative activity, some studies using proliferative markers (e.g., Ki-67) have reported a low proliferation rate in breast-ACC $[8,10]$. The patient in this case report has a low proliferation rate (10\%). C-kit, a transmembrane tyrosine kinase receptor protein encoded by the proto-oncogene KIT, is highly expressed in ACC of the salivary gland (89-100\%) and that of the breast (83-100\%) [11, 12]. In $65 \%$ of cases, overexpression of epidermal growth factor receptor (EGFR) can be found [1], and the EGFR protein is commonly expressed in the absence of EGFR gene alterations [8], but EGFR was not detected in this patient.

Breast-ACC usually has an excellent prognosis, in contrast with other TNBCs. The 5-year and 10 -year survival rates are $>95 \%$ and $90 \%$, respectively, and lymph node metastasis is rare, as well as distant metastases, which affect mainly visceral organs $[2,13]$. Based on its inactive clinical course and favorable outcome, treatment for breast-ACC is generally breast-conserving surgery. If the tumor has a high-grade pattern, it will be cured by simple mastectomy. Coates et al. [14] reported a considerable benefit of adjuvant radiotherapy on overall and disease-specific survival in patients with breast-ACC. The patient here did not undergo radiotherapy. Furthermore, the role of systemic adjuvant chemotherapy for breast-ACC patients remains controversial. Systemic adjuvant chemotherapy for patients with high-grade lesions or axillary lymph node/distant metastasis may be beneficial. Breast-ACC rarely spreads via the lymphatic system and rarely involves the regional lymph nodes. Mhamdi et al. [15] reported a case of breast-ACC where metastases developed in the lung, kidney, and brain. The most frequent site of a metastasis is the lung. A recent study [16] has reported the lenvatinib has a good and positive antitumor activity in patients (phase II) with metastatic ACCs (with breast primary), it might demonstrate a new direction for the treatment of breast-ACCs. Researchers need to put more attention to the development of lenvatinib. Currently, there is still conflict on the optimal treatment modalities for breast-ACC, and this disease also lacks some evidence with respect to endocrine therapy and targeted therapy. Thus, more research is needed in order to establish the optimal guidelines for the treatment of breast-ACC. 


\section{Acknowledgments}

This work was supported by self-funded Program of Chengde Science and Technology Division (No. 201706A055).

\section{Conflict of interest}

The authors declare no conflict of interest.

\section{References}

1. Lakhani SR, Ellis IO, Schnitt SJ, Tan PH, van de Vijver MJ. WHO Classification of Tumours of the Breast. $4^{\text {th }}$ ed. IARC Press, Lyon 2012; 56-7.

2. Miyai K, Schwartz MR, Divatia MK, et al. Adenoid cystic carcinoma of breast: Recent advances. World J Clin Cases 2014; 2: 732-41.

3. Rosen PP. Adenoid cystic carcinoma of the breast a morphologically heterogenous neoplasm. Pathol Ann 1989; 24: 237-54.

4. Wang S, Ji X, Wei Y, Yu Z, Li N. Adenoid cystic carcinoma of the breast: review of the literature and report of two cases. Oncol Letters 2012; 4: 701-4.

5. McClenathan JH, de la Roza G. Adenoid cystic breast cancer. Am J Surg 2002; 183: 646-9.

6. Tavassoli FA, Eusebi V. Carcinomas of low-grade malignancy. Adenoid cystic carcinoma. In: Tavassoli FA, Eusebi V. Tumors of the mammary gland. AFIP atlas of tumor pathology. 4th series; fasc. 10. Washington, D.C, USA: American Registry of Pathology in collaboration with the Armed Forces Institute of Pathology, 2009: 183-7.

7. Badve S, Dabbs DJ, Schnitt SJ, et al. Basal-like and triplenegative breast cancers: a critical review with an emphasis on the implications for pathologists and oncologists. Mod Pathol 2011; 24: 157-67.

8. Wetterskog D, Lopez-Garcia MA, Lambros MB, et al. Adenoid cystic carcinomas constitute a genomically distinct subgroup of triple-negative and basal-like breast cancers. J Pathol 2012; 226: 84-96.

9. Reyes C, Jorda M, Gomez-Fernández C. Salivary glandlike tumors of the breast express basal-type immunohistochemical markers. Appl Immunohistochem Mol Morphol 2013; 21: 283-6.

10. Pastolero G, Hanna W, Zbieranowski I, Kahn HJ. Proliferative activity and $p 53$ expression in adenoid cystic carcinoma of the breast. Mod Pathol 1996; 9: 215-9.

11. Bhutani N, Kajal P, Singla S. Adenoid cystic carcinoma of the breast: experience at a tertiary care centre of Northern India. Int I Surg Case Rep 2018; 51: 204-9.

12. Crisi GM, Marconi SA, Makari-Judson G, Goulart RA. Expression of c-kit in adenoid cystic carcinoma of the breast. Am J Clin Pathol 2005; 124: 733-9.

13. Ghabach B, Anderson WF, Curtis RE, Huycke MM, Lavigne JA, Dores GM. Adenoid cystic carcinoma of the breast in the United States (1977 to 2006): a population-based cohort study. Breast Cancer Res 2010; 12: R54.

14. Coates JM, Martinez SR, Bold RJ, Chen SL. Adjuvant radiation therapy is associated with improved survival for adenoid cystic carcinoma of the breast. J Surg Oncol 2010; 102: 342-7.

15. Mhamdi HA, Kourie HR, Jungels C, Aftimos P, Belbaraka R, Piccart-Gebhart M. Adenoid cystic carcinoma of the breast an aggressive presentation with pulmonary, kidney, and brain metastases: a case report. J Med Case Rep 2017; 11: 303.
16. Tchekmedyian V, Sherman EJ, Dunn L, et al. Phase ॥ study of lenvatinib in patients with progressive, recurrent or metastatic adenoid cystic carcinoma. J Clin Oncol 2019; 37: 1529-37. 